\title{
Cryptotanshinone Inhibites Bladder Cancer Cell Proliferation and Promotes Apoptosis via the PTEN/PI3K/AKT Pathway
}

\author{
Yadong Liu' ${ }^{1}$ Fanlu Lin ${ }^{1,2}$, Yaodong Chen ${ }^{3}$, Rui Wang ${ }^{1}$, Jiannan Liu ${ }^{1}$, Yinshan Jin ${ }^{1}$, and Ruihua An ${ }^{\bowtie}$ \\ 1. Department of Urology. The First Affiliated Hospital of Harbin Medical University, Harbin, Heilongiiang, 150001, People's Republic of China; \\ 2. Department of Urology. Linyi Central Hospital, Linyi, Shandong, 276400, People's Republic of China; \\ 3. Department of ultrasonic imaging, First Hospital of Shanxi Medical University, Taiyuan, 030001, China. \\ $\triangle$ Corresponding author: Ruihua An, Department of Urology, the First Affiliated Hospital of Harbin Medical University, No.23 You Zheng Street, Harbin \\ 150001, Heilongjiang, China. E-mail: 0086-451-85555830 Tel.: 0086-451-85555830
}

(c) The author(s). This is an open access article distributed under the terms of the Creative Commons Attribution License (https://creativecommons.org/licenses/by/4.0/). See http://ivyspring.com/terms for full terms and conditions.

Received: 2018.11.12; Accepted: 2019.09.22; Published: 2020.01.01

\begin{abstract}
Cryptotanshinone (CTT), extracted from the root of Salvia miltiorrhiza Bunge (Danshen), exhibits activities against a variety of human cancers in vitro and in vivo. The purpose of this study was to investigate the potential inhibitory effect of CTT on bladder cancer. In this study, we found that CTT inhibited bladder cancer cell proliferation, migration, and invasion and promoted apoptosis. In addition, CTT modulated the expression of proteins via the PI3K/AKT pathway, and the inhibition of PI3K/AKT signalling was due to induction of PTEN expression. Taken together, the results of the present study demonstrated the anticancer effect of CTT on bladder cancer cells, which might be associated with the downregulation of $\mathrm{PI} 3 \mathrm{~K} / \mathrm{AKT} / \mathrm{mTOR}$ and NF-KB signalling pathway proteins, and this inhibition was mediated by the induction of PTEN.
\end{abstract}

Key words: cryptotanshinone; bladder cancer; proliferation; apoptosis; PTEN/PI3K/AKT.

\section{Introduction}

Bladder cancer is the 7 th most common tumour worldwide in males, while it is the 17th most common tumour in females and is one of the most deadly urothelial malignancies [1]. Almost three-quarters of newly diagnosed bladder cancer cases are non-muscle-invasive bladder cancer (NMIBC), which can be treated with transurethral resection of the tumours followed by intravesical instillation of chemotherapeutic drugs [2]. However, bladder cancers have a high recurrence rate, and it is estimated that $25 \%$ of patients with NMIBC develop muscle-invasive bladder carcinoma following treatment [3]. Once bladder cancer develops into the invasive stage, the prognosis and treatment become limited [4]. Although various anticancer agents, such as radiotherapy, chemotherapy and hyperthermia, have been shown to inhibit tumour recurrence and progression, their toxic side effects and limited response rate remain major clinical problems [5-7]. Therefore, novel or alternative agents with fewer side effects for bladder cancer patients are urgently required.

Numerous studies have confirmed that the phosphatidylinositol-3 kinase (PI3K)/Akt (protein kinase B)/mammalian target of rapamycin (mTOR) pathway plays an important role in cell proliferation, metastasis and angiogenesis in bladder cancer $[8,9]$. Moreover, studies have demonstrated that blocking the PI3K/Akt/mTOR pathway can be a potential therapeutic strategy [10]. For example, an mTOR inhibitor called everolimus could significantly prevent the growth of bladder carcinoma in vitro and in vivo [11]. Moreover, NVP-BEZ235, a dual PI3K and mTORC1/2 inhibitor, exhibits strong antitumour activity in bladder cancer studies [12]. Therefore, the PI3K/Akt/mTOR pathway might be a potential 
target for the treatment of bladder cancer [13].

Cryptotanshinone (CTT) is extracted from the root of Salvia miltiorrhiza Bunge (Danshen) and has numerous pharmacological effects, including antioxidant, anti-hyperlipidaemia, anti-inflammation and anti-diabetes effects [14, 15]. Moreover, numerous studies have shown that CTT exhibits activities against a variety of human cancers in vitro and in vivo and can be used for the management of human leukaemia, colorectal cancer, pancreatic cancer, breast cancer, prostate cancer, liver cancer, and gastric carcinoma [16-18]. However, the potential effect of CTT on bladder cancer and its mechanism remain unknown.

\section{Materials and Methods}

\section{Reagents and chemicals}

5637 and T24 cells were donated by $\mathrm{Xu}$ Qingquan from the Urology Laboratory of People's Hospital affiliated with Peking University Medical College. CTT was purchased from Shanghai Aladdin Biochemical Technology Co., Ltd. (Shanghai, China), and purity was assessed by HPLC ( $>98 \%)$. CTT was dissolved in methanol at $80 \mathrm{mmol} / \mathrm{L}$ stock concentration and stored at $-20^{\circ} \mathrm{C}$. CTT was then dissolved and diluted in culture medium at the appropriate concentrations in all cell experiments. The CTT structure is shown in Figure 1. RPMI-1640 medium and foetal bovine serum (FBS) were obtained from HyClone (Thermo Fisher Scientific, Waltham, MA, USA). Cell Counting Kit 8 (CCK-8 Kit) was purchased from Dojindo Molecular Technologies. Propidium iodide (PI) was purchased from Sigma-Aldrich Chemical Company (St. Louis, MO, USA). Rabbit antibodies against mouse cleaved caspase-9, cleaved caspase-3, Bcl-2, Bax, matrix metalloproteinase-2 (MMP-2), matrix metalloproteinase-9 (MMP-9), vimentin, E-cadherin, PI3K, phosphatase and tensin homologue (PTEN), p-mTOR (Ser2448), p-AKT (Ser473), AKT, NF-kB and $\beta$-actin were obtained from Cell Signaling Technology (Danvers, MA, USA). Primary antibodies for detecting Bad and Bcl2L2 were all purchased from Abcam (Cambridge, UK). The secondary antibodies, including HRP-conjugated AffiniPure goat anti-rabbit IgG and HRP-conjugated AffiniPure goat anti-mouse IgG, were purchased from ZhongShan Golden Bridge Bio Co., Ltd. (Beijing, China).

\section{Cell culture}

Two human bladder carcinoma cell lines, 5637 and T24, were grown in RPMI-1640 containing 10\% (v/v) FBS, $100 \mathrm{U} / \mathrm{mL}$ penicillin and $100 \mu \mathrm{g} / \mathrm{mL}$ streptomycin. Cells were cultured at $37^{\circ} \mathrm{C}$ in a $5 \% \mathrm{CO}_{2}$ humidified environment.

\section{Cell viability assay}

The proliferation and cytotoxicity of cells were determined using a CCK-8 assay (Dojindo Molecular Technologies, Beijing, China). A total density of approximately $5 \times 10^{3}$ cells/well 5637 and T24 cells was seeded in 96-well plates for $24 \mathrm{~h}$. The cells were treated with different concentrations of CTT in $200 \mu \mathrm{L}$ per well and incubated at $37^{\circ} \mathrm{C}, 5 \% \mathrm{CO}_{2}$ for 24,48 , and $72 \mathrm{~h}$. Subsequently, CCK-8 was added to each well and incubated in a high-humidity environment at $37^{\circ} \mathrm{C}$ and $5 \% \quad \mathrm{CO}_{2}$ for $1 \mathrm{~h}$. The absorbance was measured at a wavelength of $450 \mathrm{~nm}$.

\section{Apoptosis assay}

5637 or T24 cells were plated in 6-well plates at a density of $5 \times 10^{5}$ cells/well and incubated with 0,20 or $40 \mu \mathrm{M}$ CTT for $48 \mathrm{~h}$ at $37^{\circ} \mathrm{C}$. Flow cytometry (BD Biosciences, Franklin Lakes, NJ, USA) and Hoechst 33258 (Wanleibio, Shenyang, China) staining were used to measure the apoptosis of the two cell lines. The relative amount of Annexin V-fluorescein isothiocyanate-positive/propidium iodide-negative cells were detected using an Apoptosis Detection Kit I (BD Biosciences) and analysed using FlowJo 7.6.1 (BD Biosciences).

\section{Colony formation}

T24 or 5637 cells were seeded into 6-well plates at a density of $1 \times 10^{5}$ cells/well in $2 \mathrm{~mL}$ of medium. After treatment with various concentrations of CTT for $48 \mathrm{~h}$, the cells were collected and diluted in fresh medium in the absence of CTT and then reseeded into 6-well plates at a density of $1 \times 10^{3}$ cells/well. Following incubation for 8 days in a $37^{\circ} \mathrm{C}$ humidified incubator with $5 \% \mathrm{CO}_{2}$, the formed colonies were fixed with $10 \%$ formaldehyde, stained with $0.1 \%$ crystal violet and counted. Cell survival was calculated by normalizing the survival of the control cells to $100 \%$.

\section{Cell invasion assay}

For the invasion assay, $50 \mu \mathrm{L}$ of Matrigel matrix was added to the upper surface before adding cells. After four hours, cells were collected and resuspended in RPMI, and then, $200 \mu \mathrm{L}$ of the cell suspension $\left(10^{5}\right.$ cells $)$ was placed in transwell chambers (CORNING, Corning, NY, USA) in 24-well plates $48 \mathrm{~h}$ after CTT treatment. Then, $500 \mu \mathrm{L}$ of RPMI medium supplemented with $10 \%$ FBS was added to the lower chamber. After culture for $24 \mathrm{~h}$, the cells in the upper layer were wiped away using cotton swabs, while the cells in the lower layer were fixed with $4 \%$ paraformaldehyde and stained with $0.1 \%$ crystal violet (Beyotime Institute of Biotechnology, Shanghai, China) for $40 \mathrm{~min}$. The cells in the lower compartment 
were those that had invaded. We counted five randomly selected fields to calculate the average cell number in triplicate.

\section{Wound-healing assay}

T24 or 5637 cells were plated in 6-well cell culture plates for $24 \mathrm{~h}$ in $2 \mathrm{~mL}$ of RPMI medium containing $10 \%$ FBS. After the cells formed a confluent monolayer, the cells were scraped with a pipette tip, and the cells were cultured in medium containing different concentrations of CTT $(0,2,4$, or $8 \mu \mathrm{M})$. After $24 \mathrm{~h}$, the cell migration distance was examined. Measurements of the wound width were made at the beginning of the experiment and $24 \mathrm{~h}$ later. Measurements were made at $20 \times$ magnification using an ocular grid.
A<smiles>CC1COC2=C1C(=O)C(=O)c1c2ccc2c1CCCC2(C)C</smiles>

CTT
B

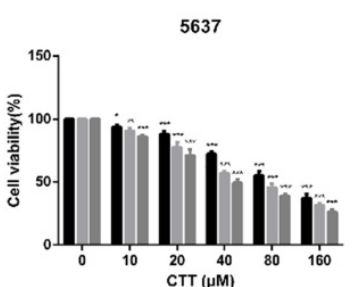

(CTT $\mu \mathrm{M})$

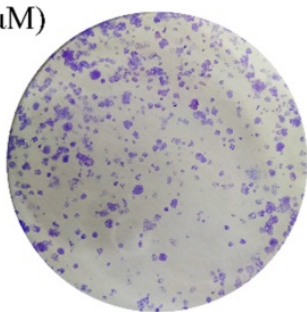

40

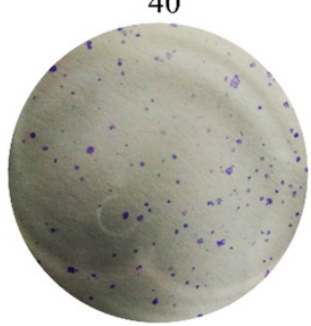

T24

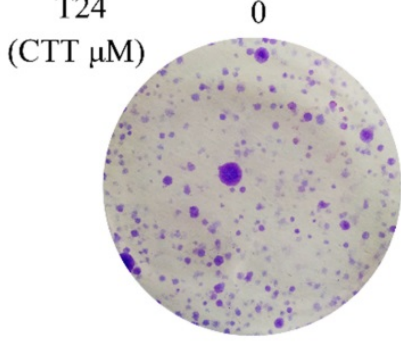

40

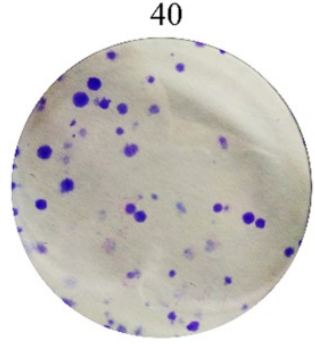

20

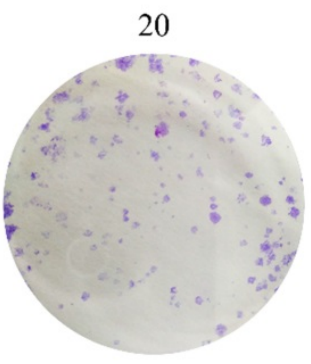

80

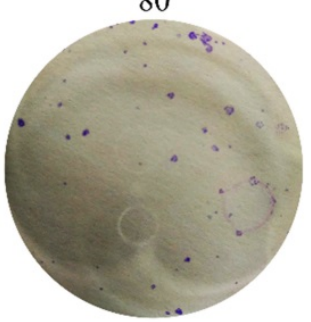

20

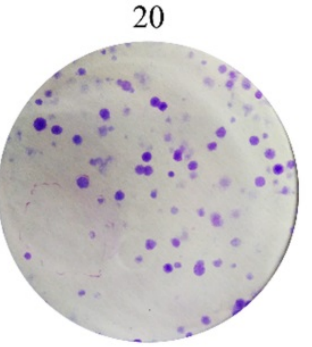

80

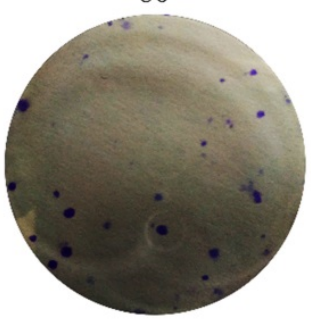

C

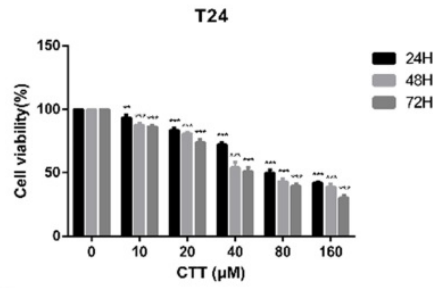

E

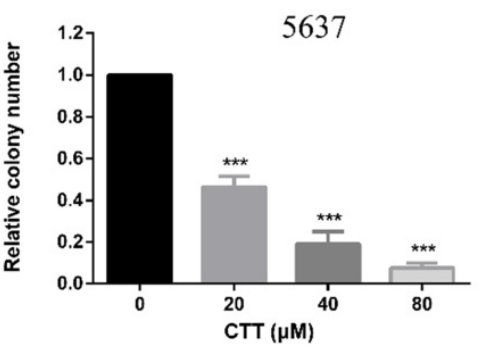

Figure 1. Effect of cryptotanshinone on the viability of bladder cancer cells. (A) Chemical structure of CTT. (B, C) Bladder cancer cell lines (5637, T24) were treated with various concentrations of CTT $(0,10,20,40,80$ or $160 \mu \mathrm{M})$ for 24,48 and 72 h. Cell viability was measured by a CCK-8 assay. (D) Anti-proliferation effect of CTT on 5637 and T24 cells by colony formation assay. (E) Histograms show the colony numbers of 5637 and T24 cells. The data shown are representative of at least three independent experiments. ${ }^{*} P<0.05$, ${ }^{* *} P<0.01$, ${ }^{* * *} P<0.001$, compared with the control group. 


\section{Gene silencing}

Human 5637 cells were seeded into 6-well plates $\left(2.5 \times 10^{5}\right.$ cells/well $)$ and allowed to adhere for $24 \mathrm{~h}$ before treatment with CTT. Using Lipofectamine 2000 (Invitrogen, Groningen, Netherlands), the cells were transfected with siRNAs directed against human 5637 cells (PTEN siRNA; GenePharma, Shanghai, China) or with non-targeted control siRNAs (NC siRNA; GenePharma).

\section{Immunofluorescence}

After treatment with different concentrations of CTT, bladder cells were washed with cold phosphate-buffered saline (PBS) twice and fixed in $4 \%$ paraformaldehyde for $30 \mathrm{~min}$. Following fixation, cells were then washed with PBS three times for 15 min and then permeabilized with $0.5 \%$ Triton X-100 for $20 \mathrm{~min}$ at room temperature. Cells were then washed with PBS three more times before incubating with primary antibodies against p-Akt and PTEN (1:100 dilution) at $4^{\circ} \mathrm{C}$. The next day, the slides were stained with corresponding FITC-conjugated secondary antibodies for $2 \mathrm{~h}$ at room temperature. The nuclei were then stained with the DNA-binding dye 4',6-diamidino-2-phenylindole dihydrochloride (DAPI) for $5 \mathrm{~min}$ and examined by fluorescence microscopy (Leica DMI3000B, Leica Microsystems, Wetzlar, Germany).

\section{Western blot analysis}

The treated cells were washed with PBS and lysed with RIPA buffer, phosphatase inhibitors and PMSF at a ratio of 100:10:1 to obtain total protein for Western blotting. Equal amounts of proteins were separated by SDS-PAGE and transferred to a polyvinylidene fluoride membrane. After transfer, the polyvinylidene fluoride membrane was blocked in 5\% fat-free milk/1 $\times$ TBS/0.1\% Tween-20 for $1 \mathrm{~h}$ at room temperature and then incubated with primary antibodies overnight at $4^{\circ} \mathrm{C}$. Then, the membrane was washed with $1 \times$ TBS $/ 0.1 \%$ Tween-20 before incubation with secondary antibodies for $1 \mathrm{~h}$ at room temperature. The immunoreactivity was detected using an Odyssey Infrared Imaging System. The bands were quantified by measuring the band intensity for each group [19].

\section{Animal studies}

BALB/c mice (4-6 weeks old) were divided into a vehicle-treated control group $(n=6)$ and a CTT-treated group $(\mathrm{n}=6)$. All studies involving mice were carried out under protocols approved by the Animal Research Reporting of In vivo Experiments (ARRIVE) guidelines. Mouse handling was performed in accordance with an animal study protocol approved by the National Cancer Institute Animal Care and Use Committee. The mice were maintained under a standard 12-h light/12-h dark cycle, with water and chow provided ad libitum. CTT was dissolved in culture medium and then diluted in PBS buffer (v/v=1:1000). CTT ( 0 or $25 \mathrm{mg} / \mathrm{kg}$ body weight) was given to mice by a single intraperitoneal injection every 2 days for 3 weeks. After euthanasia by $\mathrm{CO}_{2}$ asphyxiation, the gallbladder, liver, duodenum, jejunum, ileum, and colon were harvested, and a small section of each tissue was excised for histological analysis. All samples were stored at $-80^{\circ} \mathrm{C}$ until analysis. The tumour size was measured in two orthogonal directions using callipers every three days, and the tumour volume $\left(\mathrm{mm}^{3}\right)$ was estimated using the equation: length $\times(\text { width })^{2} \times 0.5$. Four weeks later, the mice were sacrificed, and the tumours were resected.

\section{Statistical analysis}

All data are expressed as the mean \pm SD of three independent experiments. Statistical significance was determined using a Student's t-test or ANOVA. A P value of less than 0.05 was considered significant. A detailed description of the methods can be found in the online Supporting Information.

\section{Results}

CTT inhibited bladder cancer cell proliferation and promoted apoptosis of 5637 and T24 cells

To investigate the anti-apoptotic effect of CTT (Figure 1A), 5637 and T24 cells were treated with different concentrations of CTT $(0-160 \mu \mathrm{M})$ for 24,48 and $72 \mathrm{~h}$, and cell viability was detected by the CCK-8 assay. CTT suppressed the viability of 5637 and T24 cells in a dose- and time-dependent manner (Figure $1 \mathrm{~B}, \mathrm{C})$. Besides, the results also showed that methanol itself had little effect on cell activity (T24 and 5637) at $48 \mathrm{~h}$ (Additional file 1: Figure S1). The addition of methanol diluted 1000 times had no effect on the expression of p-Akt and PTEN protein (Additional file 2: Figure S2). In addition, the colony formation of 5637 and T24 cells was reduced significantly by CTT in a dose-dependent manner (Figure 1D). Furthermore, to investigate the anti-apoptotic effect of CTT, 5637 and T24 cells were stained with Annexin V and propidium iodide (PI), followed by flow cytometry (FCM) analysis. Figure 2A and B shows that CTT promoted the apoptosis of 5637 and T24 cells in a dose-dependent manner. To further investigate this finding, Western blotting was performed to detect the expression of important signalling proteins involved in apoptosis. The data showed that the expression level of Bax and Bad increased, the 
expression level of Bcl-2 and Bcl2L2 decreased, and the activity of caspase- 3 and -9 was enhanced, which plays a crucial role in the progression of apoptosis
(Figure 2D, E). Taken together, these findings indicate that CTT may inhibit proliferation and promote apoptosis of bladder cancer cells.

A

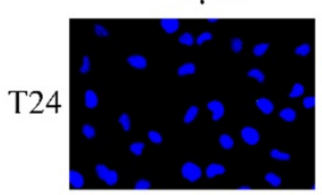

5637

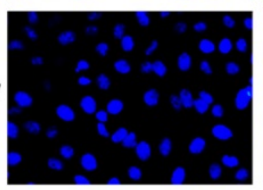

B

$B$

$0 \mu \mathrm{M}$
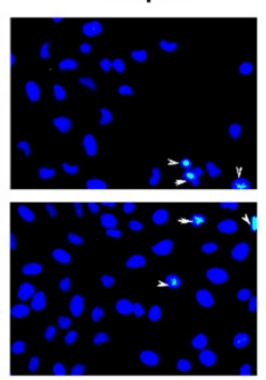

exin V-FITC / PI
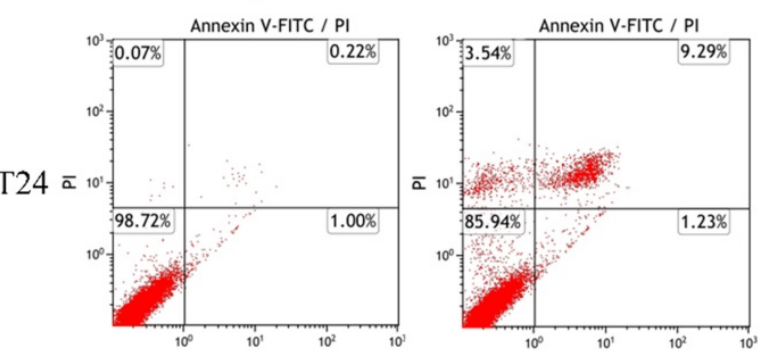

$20 \mu \mathrm{M}$
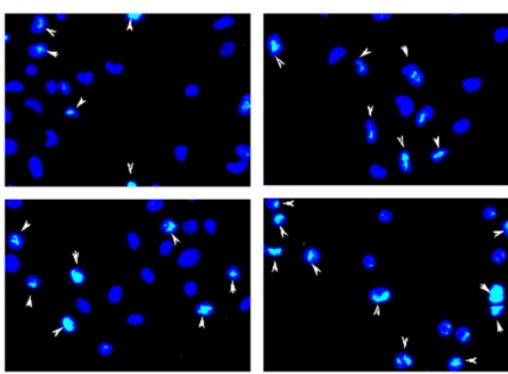

$40 \mu \mathrm{M}$
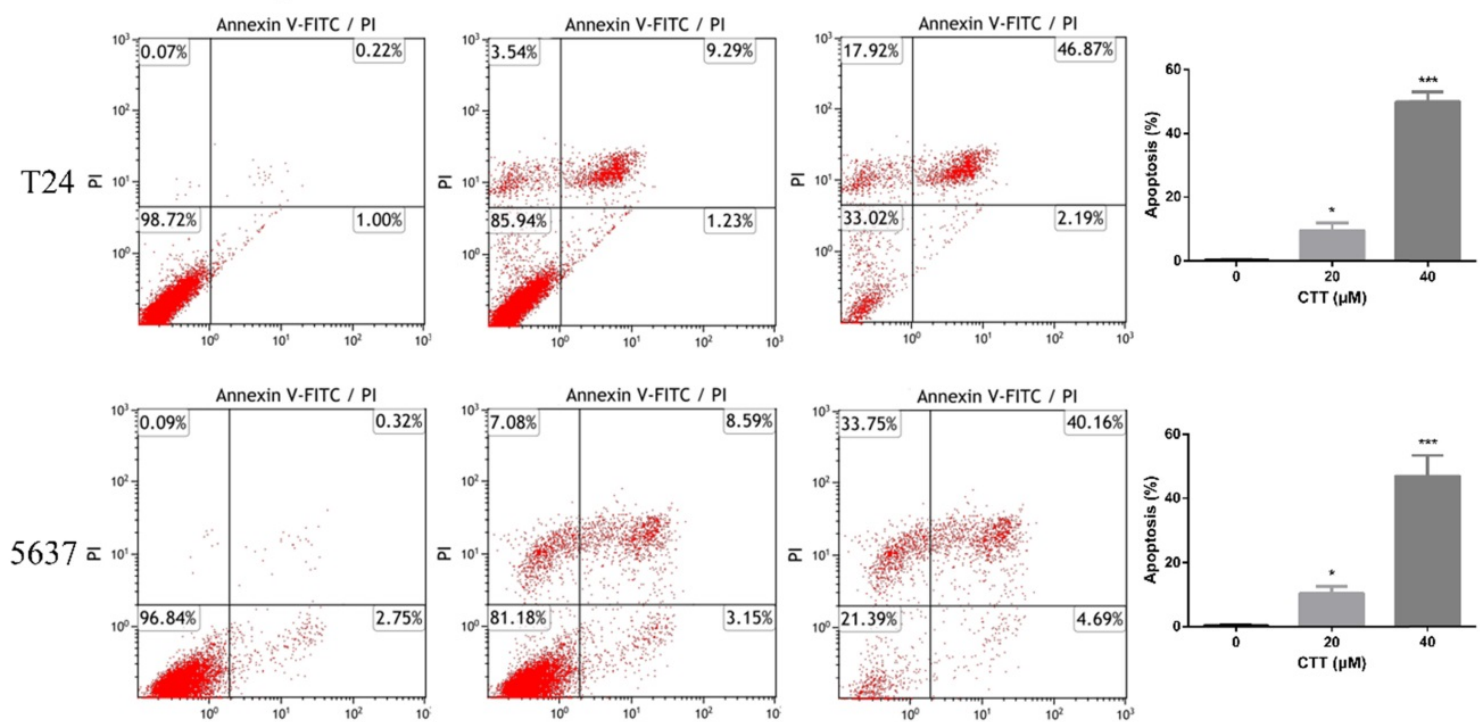

$\mathrm{C}$

$$
\text { CTT }(\mu \mathrm{M})
$$

Cleaved caspase 3

Cleaved caspase 9

$\beta$-actin
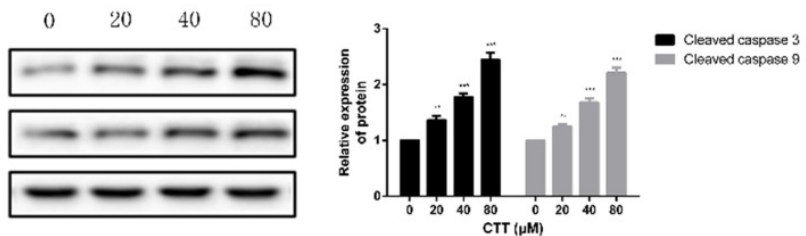

$\mathrm{D}$
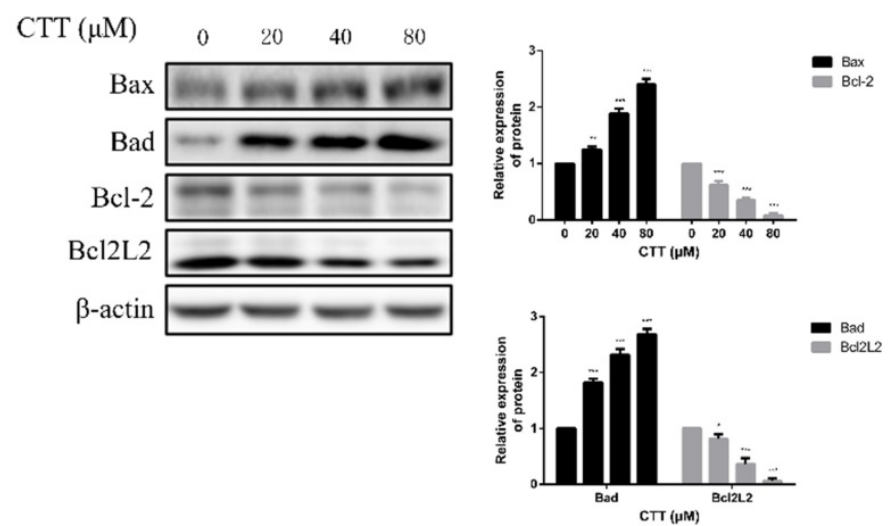

Figure 2. Effect of CTT on apoptosis of bladder cancer cells in vitro. (A) Hoechst 33258 staining was used to observe the morphology of the cell nucleus in the bladder cancer cell lines 5637 and T24 incubated with CTT ( $\times 100$ magnification). (B) Bladder cancer cells were incubated with a gradient of CTT concentrations for $48 \mathrm{~h}$. Representative flow cytometry histograms of assays performed to detect apoptosis. (C) Representative histograms for the apoptotic rate in 5637 and T24 cells. (D) Respective expression of cleaved caspase 3, cleaved caspase 9, Bcl-2, Bad, Bcl2L2 and Bax was analysed by Western blotting with $\beta$-actin as the loading control. (E) The density of each band was examined for a statistical comparison of protein expression levels normalized to the $\beta$-actin level. 
A

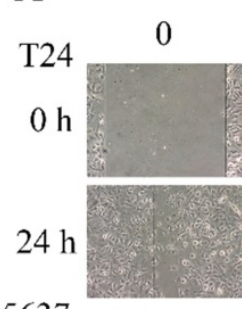

5637

$0 \mathrm{~h}$

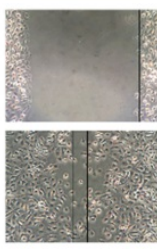

B

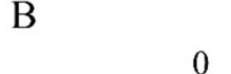

T24

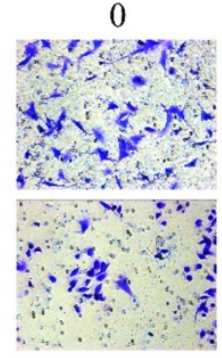

E

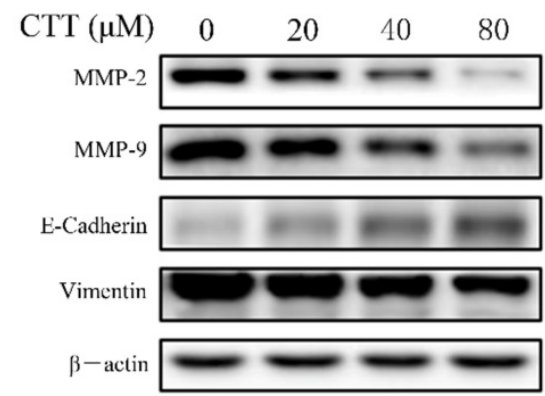

CTT
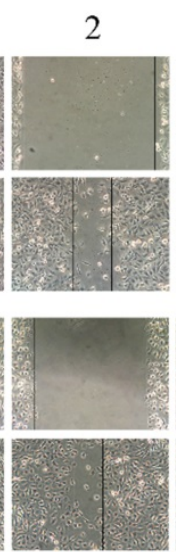

CTT

2
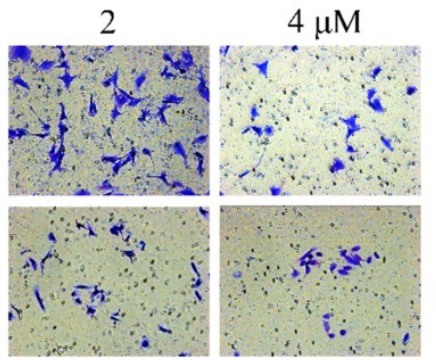

C
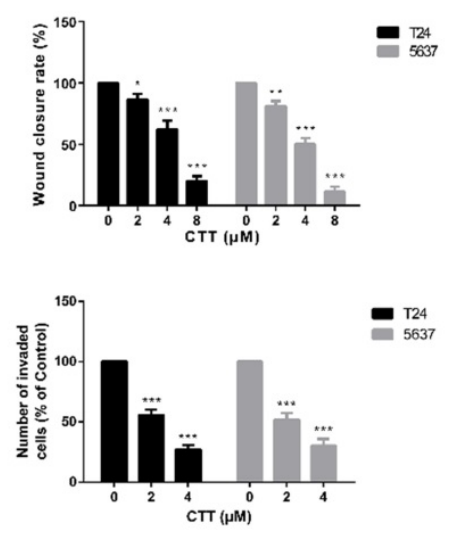

D

T24
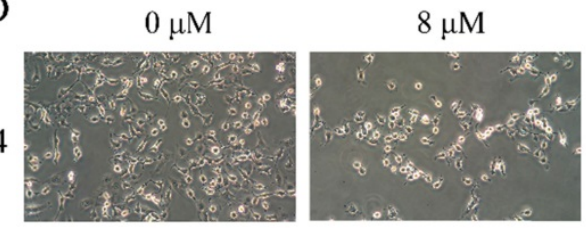

5637
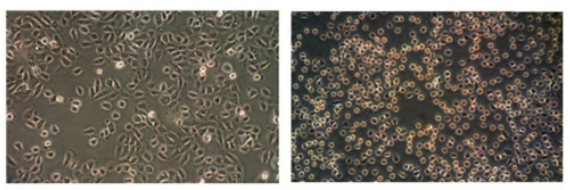

F

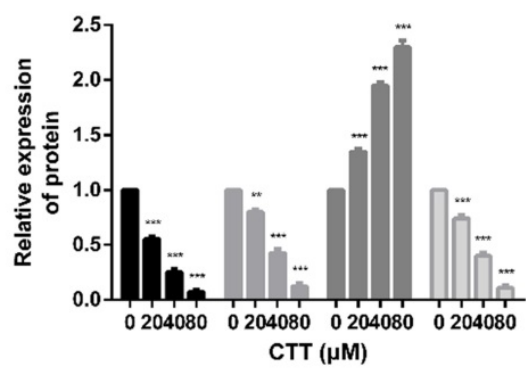

Figure 3. Wound healing assay and transwell assay were used to evaluate the effect of CTT on migration and invasion of bladder cancer cells. (A) Cells were treated with different concentration of CTT and representative images from wound healing assays were acquired at 0 and $24 \mathrm{~h}$. (B) The invasion ability of 5637 and T24 cells was also quantified by Transwell assays. (C) Histograms exhibited wound closure rate and the number of invaded cells. (D) The morphological changes of T24 and 5637 cells in the presence of CTT. (E) Role of CTT on the protein levels of MMP2, MMP9, E-cadherin and Vimentin. The relative protein levels were normalized to the $\beta$-actin level. The quantitative results were expressed as the means \pm SD of three experiments. ${ }^{*} P<0.05,{ }^{* *} P<0.01$, ${ }^{* * * *} P<0.001$, compared with control group.

\section{CTT inhibited bladder cancer cell migration and invasion}

To investigate the effect of CTT on bladder cancer cell migration and invasion, wound-healing and transwell assays were performed using 5637 and T24 cells. CTT inhibited 5637 and T24 cell migration in a dose-dependent manner (Figure 3A). Consistently, as shown in Figure 3B, the invasion ability of 5637 and T24 cells was also dose-dependently reduced by CTT in a transwell assay.

To further verify the anti-migration and anti-invasion effects of CTT, we performed experiments to investigate the inhibitory effects of CTT on the epithelial-to-mesenchymal transition
(EMT), a critical event in cell invasion and migration. We initially detected that bladder cancer cells exposed to 0 or $8 \mu \mathrm{M}$ CTT for $24 \mathrm{~h}$ exhibited an altered morphology from a fibroblast-like mesenchymal phenotype to a round epithelioid phenotype (Figure 3D). In addition, we further assessed the expression levels of migration-related proteins (E-cadherin, vimentin, MMP2 and MMP9), which are responsible for tissue remodelling and degradation of the extracellular matrix (ECM), to verify these effects. As shown in Figure 3E, CTT inhibited the expression of MMP2 and MMP9 in a dose-dependent manner. These findings indicated that CTT inhibited bladder cell migration and invasion. 
A
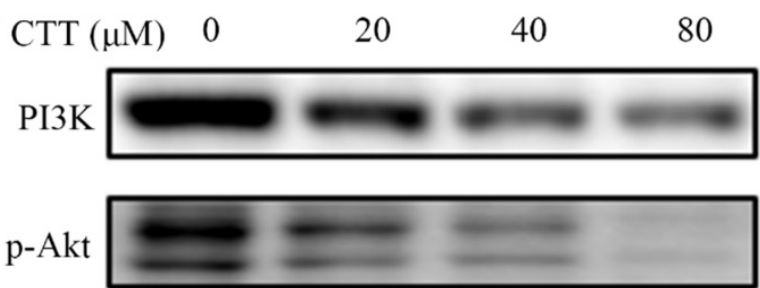

Akt
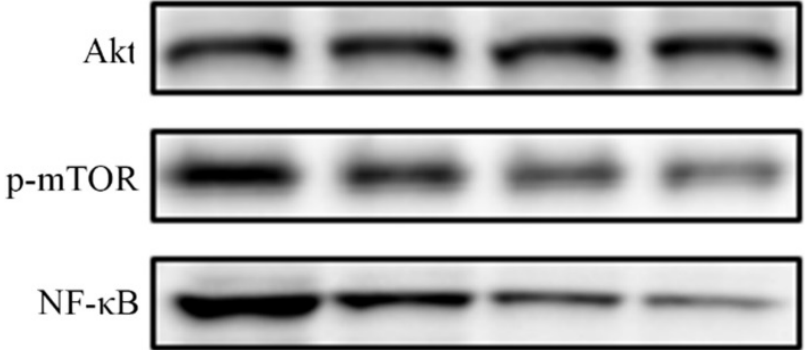

$\beta$-actin

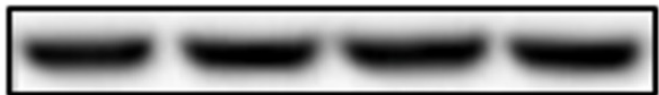

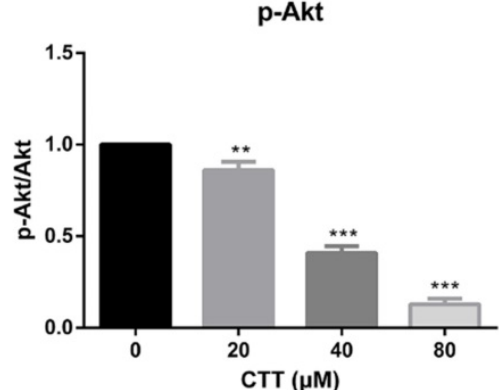
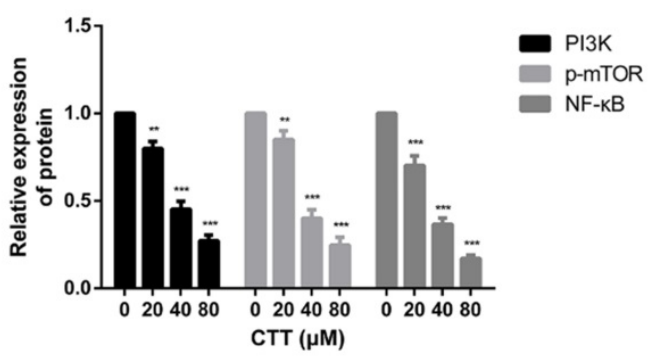

$\mathrm{B}$

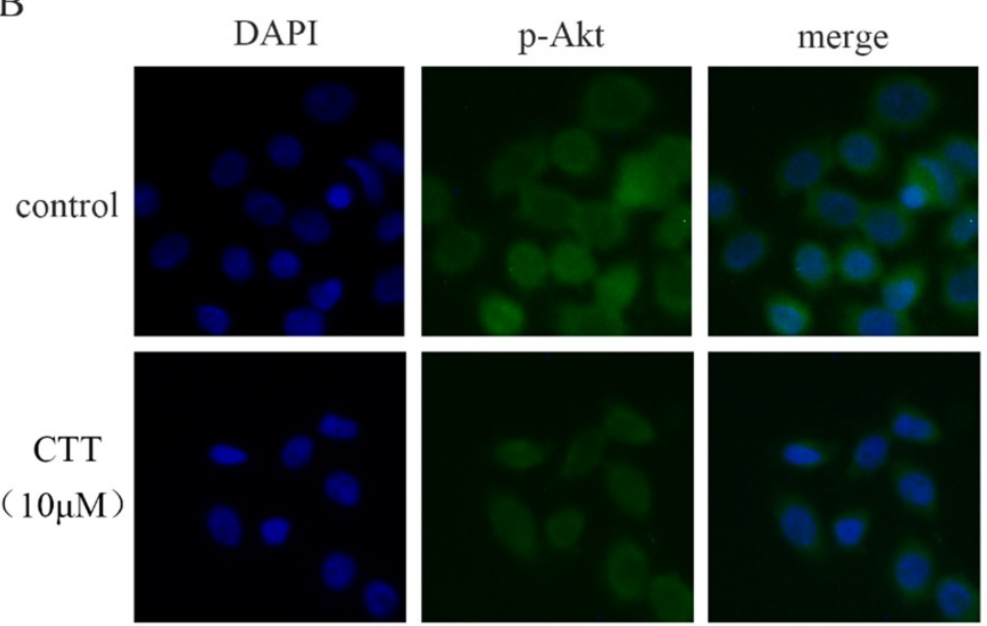

Figure 4. CTT inhibited the PI3K/Akt and mTOR, NF-KB signaling pathways. (A) After treatment with different concentrations of CTT, images of protein expression of PI3K, p-Akt, p-mTOR and NF-KB were determined by Western blot. $\beta$-actin was used as a loading control. (B) Following treatment with or without CTT for $48 \mathrm{~h}$, the expression of $\mathrm{p}$-Akt in T24 cells was assessed by immunofluorescence $(\times 200)$. Each value represented the mean \pm SD for triplicate samples. ${ }^{*} \mathrm{P}<$ $0.05, * * P<0.01, * * * P<0.001$, compared with control group.

\section{CTT modulated the expression of proteins in the PI3K/AKT pathway}

To investigate whether the PI3K/AKT pathway was involved in the antitumour effects of CTT, the expression levels of proteins involved in the PI3K/AKT pathway were explored using Western blots. The data showed that the protein expression of PI3K, p-AKT, p-mTOR and NF-KB in the treatment group was decreased compared with that of the control group after $48 \mathrm{~h}$ (Figure 4A). Consistently, an immunofluorescence assay also demonstrated a significant decrease in p-Akt due to CTT (Figure 4B).

\section{Inhibition of PI3K/AKT signalling was due to the induction of PTEN expression}

Studies have demonstrated that PTEN deficiency is the most common genetic change in bladder cancer; thus, we hypothesized that induction of PTEN was a reasonable explanation for the CTT-induced PI3K/AKT signalling pathway inhibition. As expected, Western blot data showed that PTEN expression was increased in 5637 cells following $24 \mathrm{~h}$ of CTT treatment (Figure 5A). In addition, an immunofluorescence assay confirmed the increased expression of PTEN due to CTT (Figure 5B). These findings suggested that CTT-mediated PI3K/AKT pathway inhibition was due to the upregulation of PTEN in bladder cancer cells. 


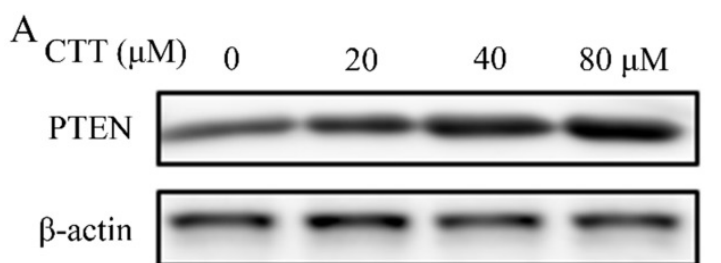

B

DAPI

PTEN
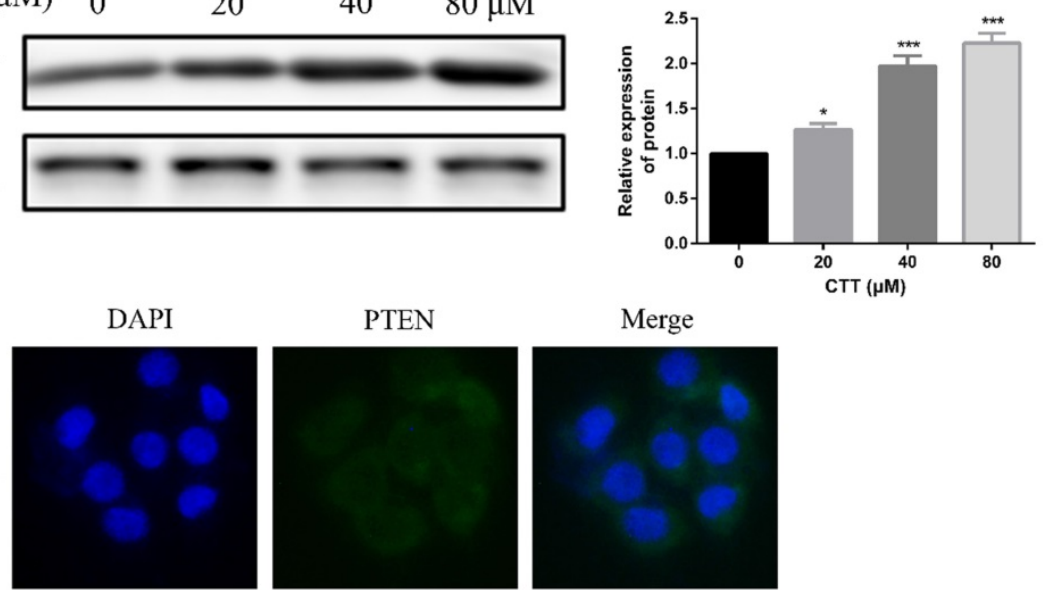

Merge

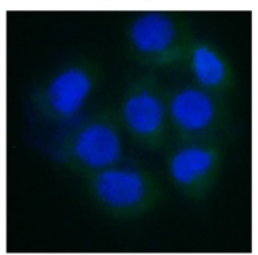

CTT

$(20 \mu \mathrm{M})$
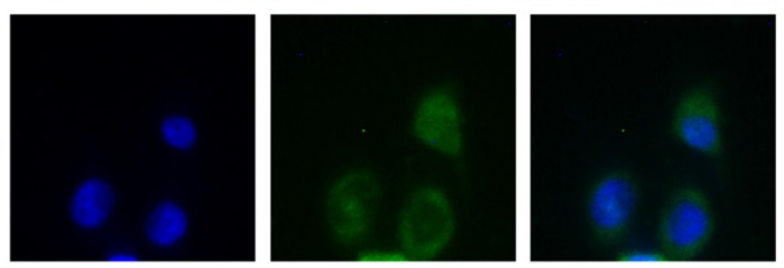

$\mathrm{C}$
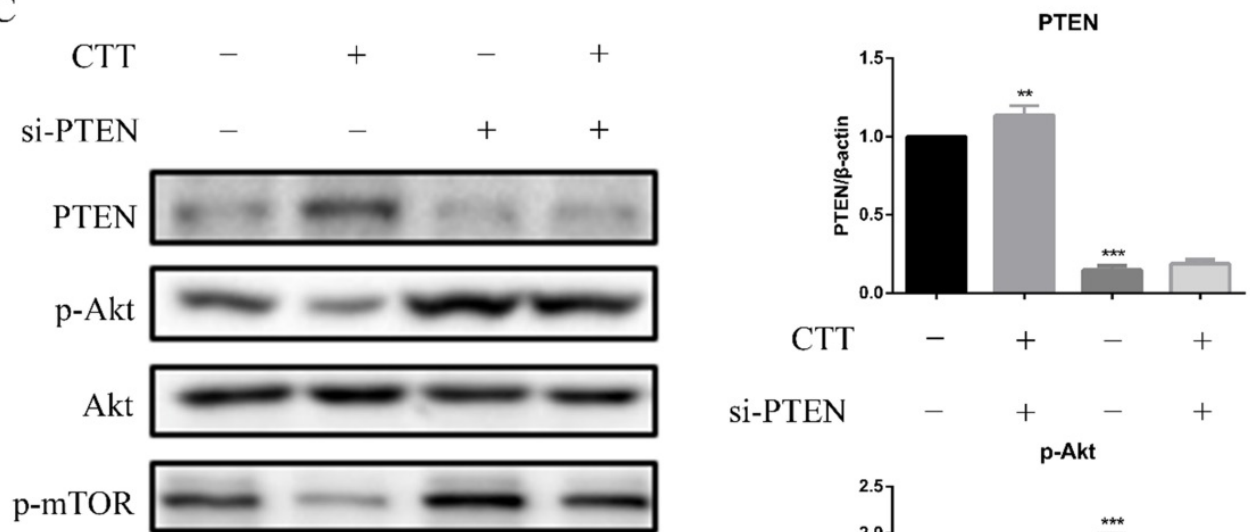

Si-PTEN
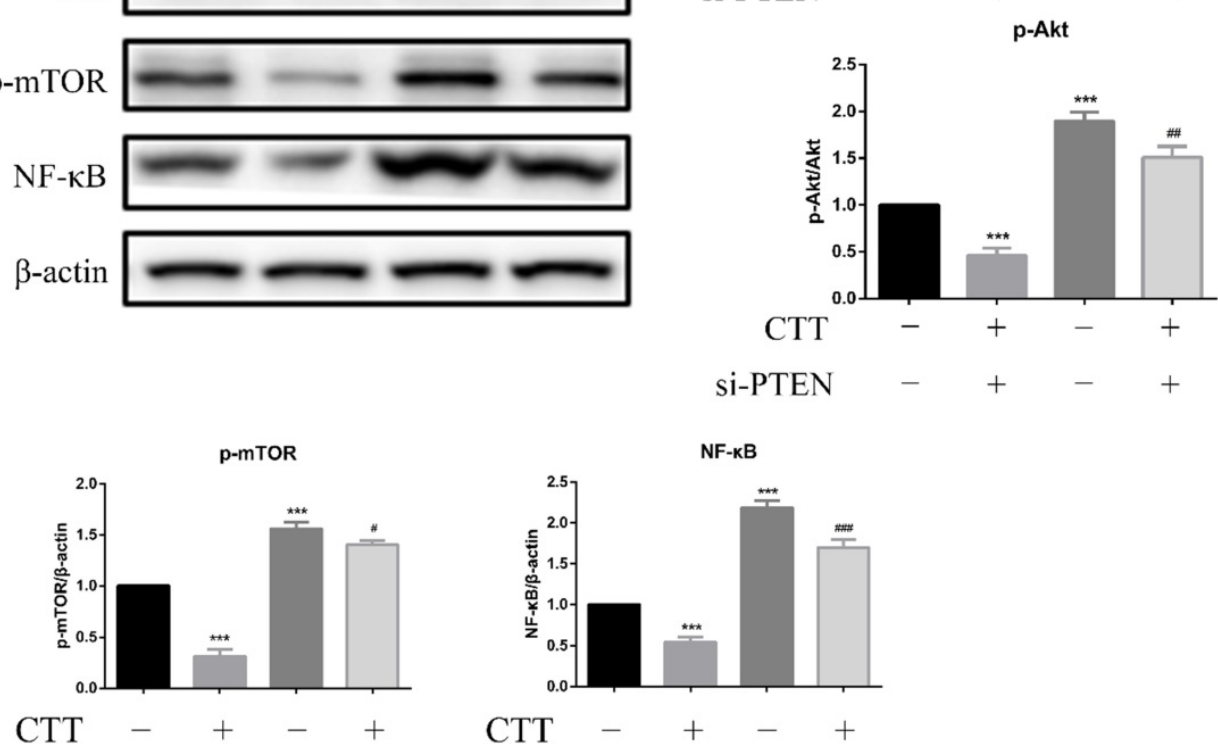

CTT

Si-PTEN $-\quad+\quad-\quad+$ Si-PTEN $-t_{-}+$

Figure 5. CTT upregulated PTEN expression in vitro. (A) Images of protein expression of PTEN was detected by Western blotting. (B) Representative immunofluorescence image images of expression of PTEN were evaluated at 0 and $24 \mathrm{~h}(\times 200)$. (C) 5637 cells were treated with CTT in presence or absence of the PTEN-siRNA, followed by Western blot analysis of the expression of PTEN, p-Akt, p-mTOR and NF-KB proteins. The results were shown as the mean \pm SD of three experiments. ${ }^{*} P<0.05,{ }^{*} P<0.01,{ }^{*} * * * 0.001$, compared with control group. 
Furthermore, we transfected specific PTEN-siRNA plasmids into 5637 cells, followed by Western blot assays. Figure $5 \mathrm{C}$ shows that this manipulation upregulated the expression of p-Akt, p-mTOR, and NF-kB. Collectively, our results demonstrated that in 5637 cells, the antitumour activity of CTT depended on the upregulation of PTEN.

\section{In vivo effects of CTT on bladder cancer}

To investigate the in vivo effects of CTT, a series of experiments were performed in nude mice. Mice subcutaneously implanted with 5637 cells were treated with a vehicle control or CTT at $25 \mathrm{mg} / \mathrm{kg}$ every 2 days for 3 weeks after xenografts were established and had grown to a mean size of $90 \mathrm{~mm}^{3}$. As shown in Figure 6A, compared with the control group, the administration of CTT in mice significantly inhibited tumour growth. Figure 6B indicates that the mean weight of tumours in the control group was 0.72 $\mathrm{g}$, whereas that of tumours in the CTT-treated group was approximately $0.31 \mathrm{~g}$. In addition, Figure 6C shows the volume change over the experimental period. We also evaluated the broad toxicity of the therapeutic drugs. As Figure 6D shows, CTT administration during the indicated periods led to no apparent toxicity-related events or significant body weight changes.

At the end of the experiment, PI3K/Akt-related proteins in tumour tissues were detected via Western blot. Figure 6E shows the downregulation of p-Akt and vimentin but the upregulation of cleaved caspase-3 and PTEN. Moreover, immunohistochemistry assays confirmed a decrease in Ki-67 and vimentin, whereas an increase in PTEN and cleaved caspase- 3 was observed. In line with these results, analysis of the in vivo experiments revealed that CTT exhibited an extreme antitumour effect on bladder cancer, and the inhibition was likely due to the inhibition of the PI3K/Akt pathway induced by the upregulation of PTEN (Figure 7).
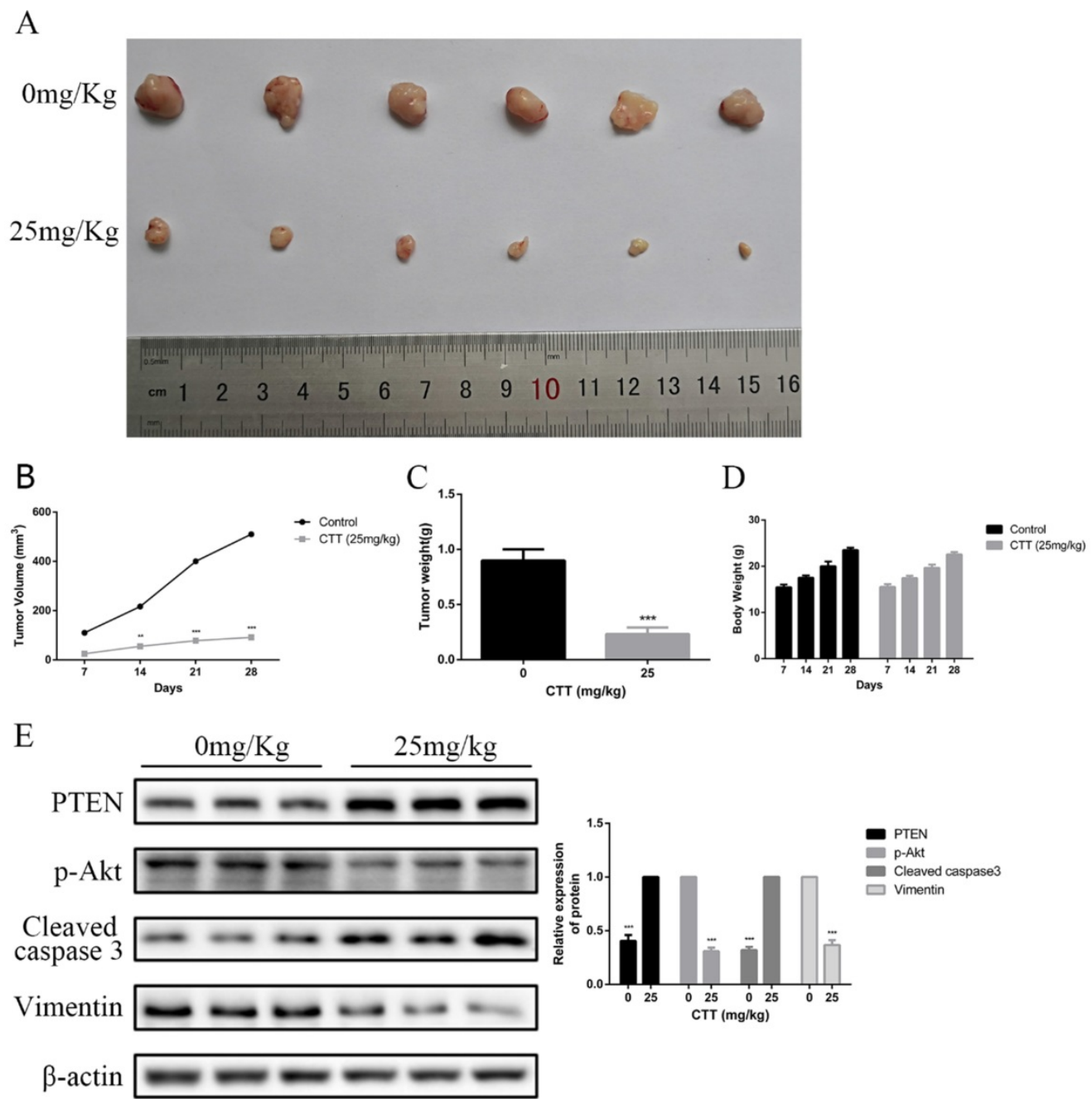

Figure 6. CTT suppressed bladder cancer growth in vivo. (A) Image showing the inhibition of a xenografted bladder tumour in nude mice treated with CTT. (B) Tumour volumes were calculated. (C) Tumour weights were measured. (D) Body weights are shown. (E) PTEN, p-Akt, cleaved caspase-3 and vimentin protein levels were quantified. The results are from at least three independent experiments. ${ }^{*} P<0.05,{ }^{* *} P<0.01$, ${ }^{* * * *} P<0.001$, compared with the control group. 
A
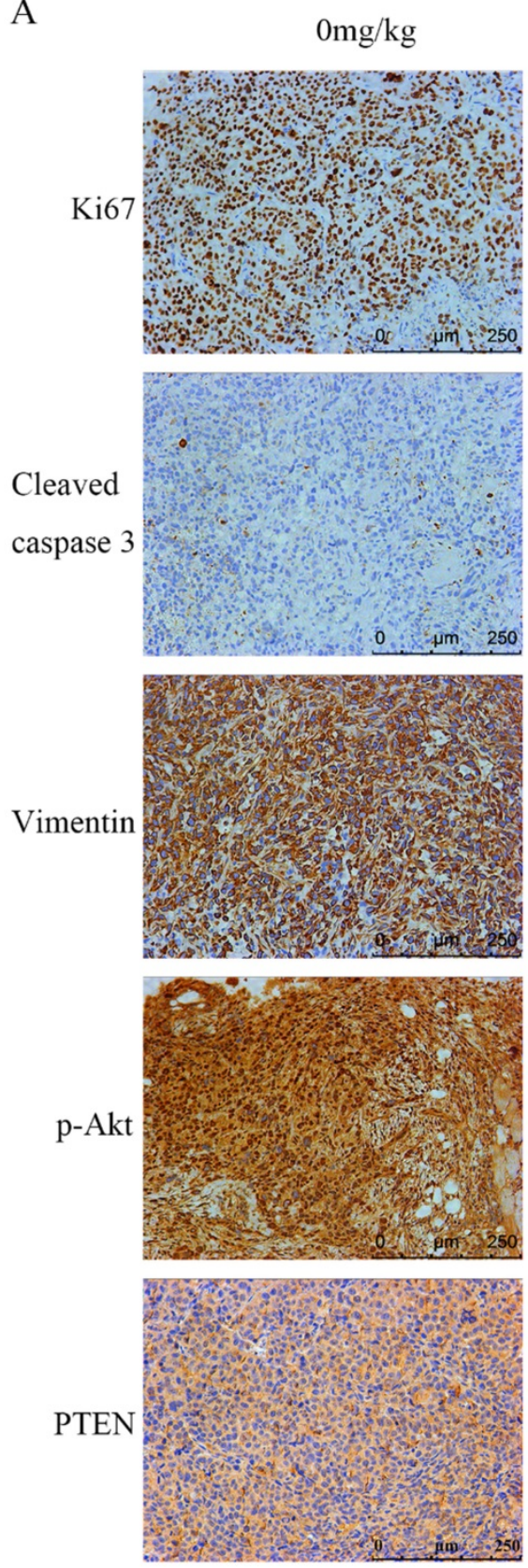

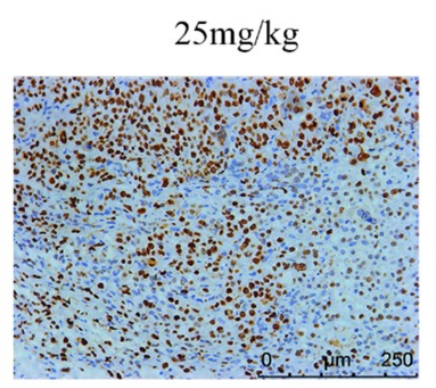

B $\quad$ Ki67
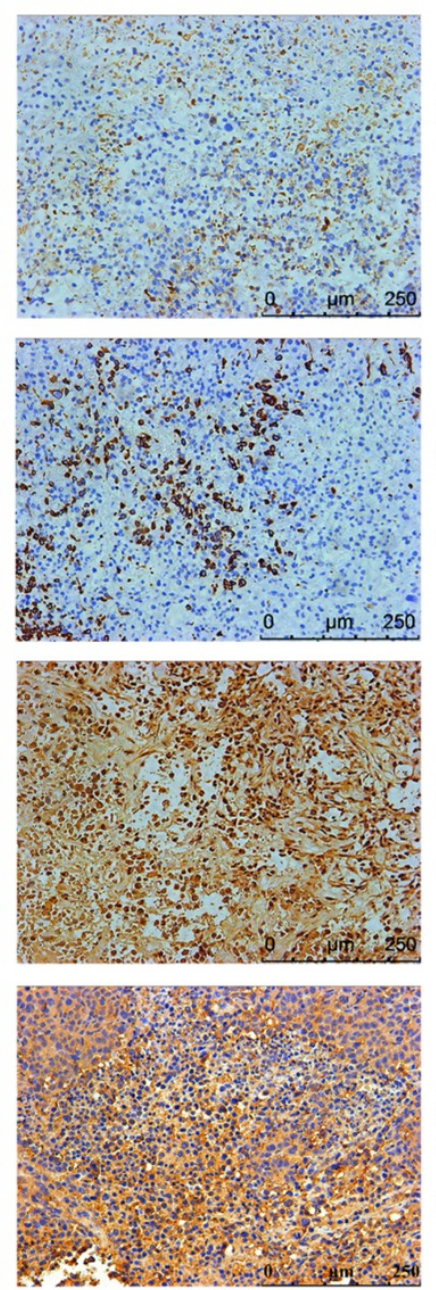

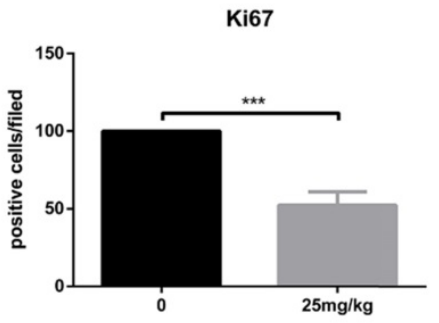

Cleaved caspase 3
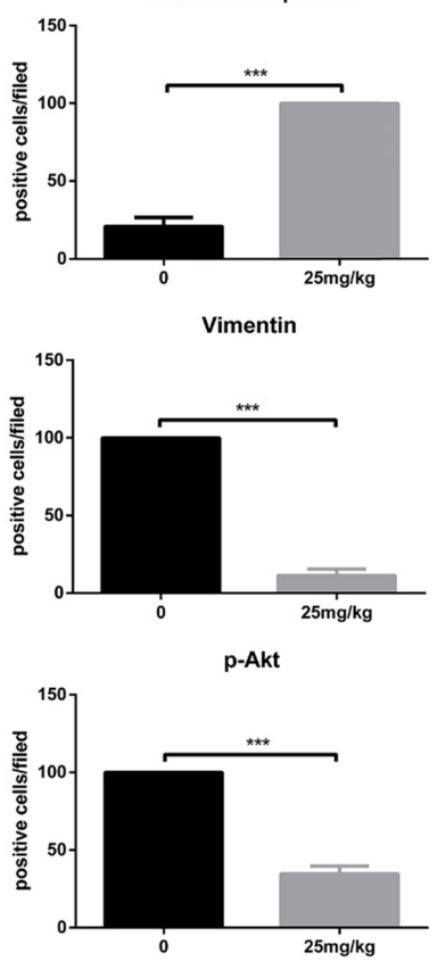

PTEN

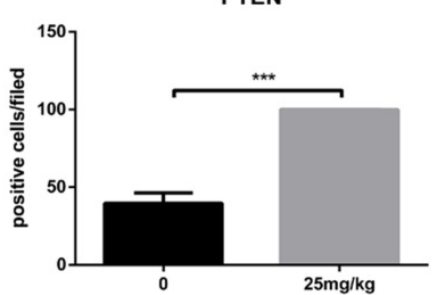

Figure 7. Effects of CTT on cell proliferation, apoptosis, and invasion in bladder tumours. Representative immunohistochemistry images of bladder tumour tissues $(\times 200)$. Level of $\mathrm{Ki}-67$, vimentin, $\mathrm{p}$-Akt were decreased, while PTEN and cleaved caspase-3 were increased, in the CTT-treated group. The values are the mean \pm SD of at least 3 independent experiments. ${ }^{*} P<0.05$, ${ }^{* *} P<0.01$, ${ }^{* * *} P<0.001$, compared with the control group.

\section{Discussion}

Multiple genes, processes and stages are involved in the development of bladder cancer [20]. Abnormalities in apoptosis and cell EMT changes have been closely correlated with bladder cancer progression [21]. Various treatment agents often inhibit tumour cells by promoting apoptosis, blocking cell cycle arrest or inhibiting cell EMT changes [22, 23]. In this study, we found that a new Akt inhibitory agent, CTT, induced significant decreases in cell proliferation and suppressed the migration and invasion of bladder cells. In addition, we found that the expression level of PTEN increased after CTT treatment, which indicated that PTEN was a key modulator of the induction of PI3K/Akt signalling [24]. Inhibition of PTEN expression reversed the inhibitory effects of CTT. Moreover, in tumourbearing mice, we showed a high propensity of CTT to inhibit proliferation and metastasis of bladder cells without apparent toxicity-related events or significant body weight changes. 


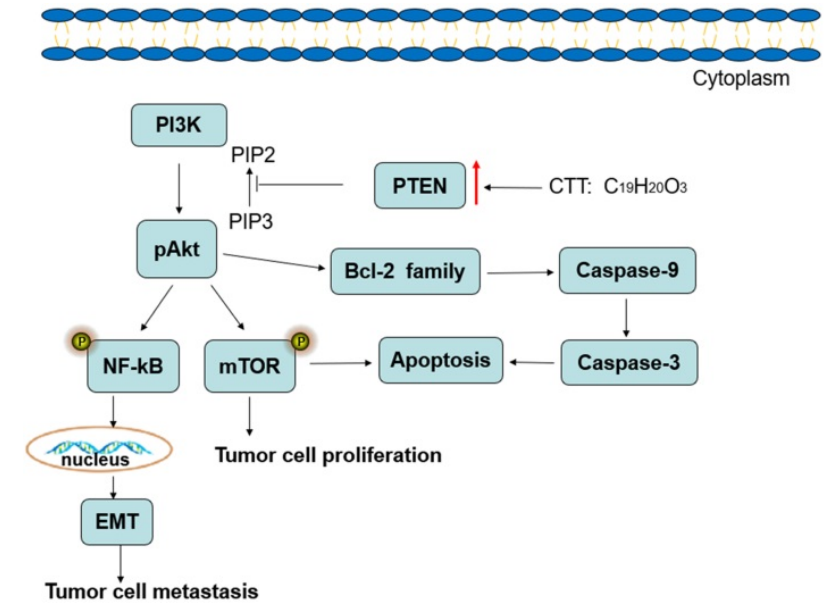

Figure 8. Diagram illustrating of the signaling pathways involved in CTT-mediated bladder cancer cell apoptosis.

CTT, a natural active element extracted from Salvia miltiorrhiza Bunge (Danshen), has antitumour activity towards a broad spectrum of cancer types, including breast cancer, liver cancer and malignancies of the alimentary tract, and it is associated with a low level of toxicity and is well tolerated by patients with cancer [25-28]. Consistent with other reports, this study showed that CTT exhibited high levels of anticancer activity on 5637 and T24 bladder cancer cells by suppressing survival and promoting apoptosis [29]. In addition, we also found that CTT could weaken bladder cancer cell migration and invasion by suppressing cell EMT changes.

However, the mechanism of CTT inhibition of bladder tumours is not fully clear. The PI3K/Akt signalling pathway is an important intracellular mediator that is critical for the regulation of cell survival and proliferation [30,31]. Numerous studies have demonstrated that aberrant activation of the PI3K/Akt pathway is involved in the pathological process of bladder cancer, and its inhibition has become a useful therapy for bladder cancer [32, 33]. Importantly, Kim et al. demonstrated that CTT induced apoptotic cell death and cell cycle arrest through the inhibition of the PI3K/AKT/GSK3B signalling pathway in human lung cancer cells [34]. Additionally, Ke et al. observed that treatment of cholangiocarcinoma cells with CTT could induce apoptosis by suppressing PI3K/AKT/NF-KB signalling pathway [35]. As Zhang et al. reported that CTT can inhibit the proliferation and migration of lung cancer cells, which was attributed to the IGF-1R-mediated phosphoinositide 3-kinase/AKT pathway [36]. Moreover, Liu et al. revealed that CTT suppresses the proliferation, growth, invasion, inflammation and angiogenesis in colon cancer cells through regulating the $\mathrm{PI} 3 \mathrm{~K} / \mathrm{AKT} / \mathrm{mTOR}$ pathway [37]. For this reason, we performed experiments to assess the inhibitory effects of CTT due to the PI3K/Akt pathway. Western blotting analyses revealed that CTT treatment significantly reduced expression of the PI3K protein. Although CTT did not regulate the expression of total Akt, it significantly suppressed its phosphorylation. Furthermore, CTT suppressed the expression of NF-kB, which mediates the effects associated with anti-apoptotic protein subcellular localization and cell viability, and mTOR, which is associated with cell behaviour, in 5637 cells. We also found that CTT inhibited the migration of 5637 bladder cancer cells though the PI3K/Akt signalling pathway. These results indicate that the inhibitory effect of CTT on bladder cancer depends on the suppression of the PI3K/Akt/mTOR and NF-kB pathways.

PTEN expression is reduced in various tumour types, such as liver, pancreatic, breast and bladder cancers, and is highly involved in regulation of tumour suppressors that downregulate AKT signalling by reducing the output of PI3K at the cell membrane [33, 38, 39]. Our research suggests that CTT might directly regulate PTEN protein stability and thus negatively regulate AKT phosphorylation. Furthermore, PTEN siRNA increased the proliferation and invasion of 5637 cells. In addition, treatment of 5637 cells with PTEN siRNA significantly increased the expression of PI3K and p-AKT. Based on these results, we propose a novel mechanism by which CTT suppresses the proliferation and invasion of bladder cancer cells by activating PTEN and thus inhibiting the PI3K/Akt pathway. However, the manner in which PTEN is modified and its stability is regulated have yet to be elucidated.

In conclusion, the results of the present study demonstrate that CTT inhibits bladder cancer cell proliferation, migration and invasion and induces cell apoptosis, which may be associated with downregulation of $\mathrm{PI} 3 \mathrm{~K} / \mathrm{AKT} / \mathrm{mTOR}$ and NF-kB signalling pathway proteins, and this inhibition is mediated by the induction of PTEN (Figure 8). Therefore, our studies provide a therapeutic agent for inhibiting the growth and metastasis of bladder cancer.

\section{Supplementary Material}

Supplementary figures.

http://www.jcancer.org/v11p0488s1.pdf

\section{Authors' contributions}

Yadong Liu, Fanlu Lin and Ruihua An: Study concept and design of the work. Yadong Liu, Fanlu Lin and Yaodong Chen: Acquisition of data. Yadong Liu and Jiannan Liu: Analysis and interpretation of data and drafting of the manuscript. Yadong Liu and 
Yinshan Jin: Critical revision of the manuscript for important intellectual content. Yadong Liu, Rui Wang: Statistical analysis. All authors read and approved the final version of the manuscript.

\section{Abbreviations}

CTT: cryptotanshinone; NMIBC: non-muscleinvasive bladder cancer; PI3K: phosphatidylinositol-3 kinase; Akt: Protein Kinase B; mTOR: mammalian target of Rapamycin; FBS: fetal bovine serum; PBS: phosphate buffered saline; EMT: Epithelial-tomesenchymal transition.

\section{Competing Interests}

The authors have declared that no competing interest exists.

\section{References}

1. Burger, Maximilian, Catto, James WF, Dalbagni, Guido, et al. Epidemiology and Risk Factors of Urothelial Bladder Cancer. Eur Urol. 2013; 63(2): 234-41.

2. Hori S, Miyake M, Tatsumi $\mathrm{Y}$, et al. Topical and systemic immunoreaction triggered by intravesical chemotherapy in an N-butyl-N-(4-hydroxybutyl) nitorosamine induced bladder cancer mouse model. Plos One. 2017; 12(4): e0175494-

3. Youssef RF, Lotan Y. Predictors of outcome of non-muscle-invasive and muscle-invasive bladder cancer. The Scientific World Journal. 2011; 11(3): 369-381.

4. Anderson B. Bladder cancer: overview and disease management. Part 1: nonmuscle-invasive bladder cancer. Br J Nurs. 2018; 27(9): S27-S37.

5. Li R, Sridharan M, Clarke A, Beesley S, Taylor H, Lees K. Comparison of Toxicity and Efficacy Outcomes of Capecitabine/MMC and 5FU/MMC in Patients with Bladder Cancer Treated with Radical Chemoradiotherapy. Clinical Oncol. 2018; 30(3): 197

6. Yang C, Chen Y, Guo W, Gao Y, Song C, Zhang Q, et al. Bismuth Ferrite-Based Nanoplatform Design: An Ablation Mechanism Study of Solid Tumor and NIR-Triggered Photothermal/Photodynamic Combination Cancer Therapy. Advanced Functional Materials. 2018: 1706827.

7. Plataniotis GA, Dale RG. Radio-chemotherapy for bladder cancer: Contribution of chemotherapy on local control. World J Radiol. 2013; 5(8): 267-74.

8. Hou T, Zhou L, Wang L, Kazobinka G, Chen Y, Zhang X, et al. Leupaxin Promotes Bladder Cancer Proliferation, Metastasis, and Angiogenesis Through the PI3K/AKT Pathway. Cell Physiol Biochem. 2018; 47(6): 2250-2260.

9. Smolensky D, Rathore K, Cekanova M. Molecular targets in urothelial cancer: detection, treatment, and animal models of bladder cancer. Drug Des Devel Ther. 2016; 10: 3305--3322.

10. Mayer IA, Arteaga CL. The PI3K/AKT Pathway as a Target for Cancer Treatment. Annual Review of Medicine. 2015; 67: annurev-med-062913-51343.

11. Chiong E, Lee IL, Dadbin A, et al. Effects of mTOR inhibitor everolimus (RAD001) on bladder cancer cells. Clin Cancer Res. 2011; 17(9): 2863-73.

12. Violeta Serra, Ben Markman, Maurizio Scaltriti, et al. NVP-BEZ235, a Dual PI3K/mTOR Inhibitor, Prevents PI3K Signaling and Inhibits the Growth of Cancer Cells with Activating PI3K Mutations. Cancer Research. 2008; 68(19): 8022-8030

13. Sathe A, Nawroth R. Targeting the PI3K/AKT/mTOR Pathway in Bladder Cancer. Methods Mol Biol. 2018; 1655: 335-50.

14. Liu C, Sun $\mathrm{H} N$, Luo $\mathrm{Y} \mathrm{H}$, et al. Cryptotanshinone induces ROS-mediated apoptosis in human gastric cancer cells. Oncotarget. 2017; 8(70): 115398-115412.

15. Luo Y, Chen W, Zhou H, Liu L, Shen T, Alexander JS, et al. Cryptotanshinone inhibits lymphatic endothelial cell tube formation by suppressing VEGFR-3/ERK and small GTPase pathways. Cancer Prevention Research. 2011; 4(12): 2083-91.

16. Ge $Y$, Cheng $R$, Zhou $Y$, Shen J, Peng $L, X u X$, et al. Cryptotanshinone induces cell cycle arrest and apoptosis of multidrug resistant human chronic myeloid leukemia cells by inhibiting the activity of eukaryotic initiation factor $4 \mathrm{E}$. Molecular \& Cellular Biochemistry. 2012; 368(1-2): 17-25.

17. Li W, Saud SM, Young MR, Colburn NH, Hua B. Cryptotanshinone, a Stat3 inhibitor, suppresses colorectal cancer proliferation and growth in vitro. Molecular \& Cellular Biochemistry. 2015; 406(1-2): 1-11.

18. Wang J, Zhang G, Dai C, Gao X, Wu J, Shen L, et al. Cryptotanshinone potentiates the antitumor effects of doxorubicin on gastric cancer cells via inhibition of STAT3 activity. Journal of International Medical Research. 2017; 45: 220-30.
19. Chen YD, Zhang Y, Dong TX, Xu YT, Zhang W, An TT, et al. Hyperthermia with different temperatures inhibits proliferation and promotes apoptosis through the EGFR/STAT3 pathway in C6 rat glioma cells. Molecular Medicine Reports. 2017; 16(6): 9401-8.

20. Chu J, Li N, Li F. A risk score staging system based on the expression of seven genes predicts the outcome of bladder cancer. Oncology Letters. 2018; 16(2): 2091-6.

21. Chen Y, Peng Y, Xu Z, Ge B, Xiang X, Zhang T, et al. LncROR Promotes Bladder Cancer Cell Proliferation, Migration, and Epithelial-Mesenchymal Transition. Cellular Physiology \& Biochemistry. 2017; 41(6): 2399-410.

22. Zhuo DX, Zhang XW, Jin B, Zhang Z, Xie BS, Wu CL, et al. CSTP1, a Novel Protein Phosphatase, Blocks Cell Cycle, Promotes Cell Apoptosis, and Suppresses Tumor Growth of Bladder Cancer by Directly Dephosphorylating Akt at Ser473 Site. Plos One. 2013; 8(6): e65679.

23. Tuo Z, Zhang J, Xue W. LncRNA TP73-AS1 predicts the prognosis of bladder cancer patients and functions as a suppressor for bladder cancer by EMT pathway. Biochem Biophys Res Commun. 2018; 499: 875-81.

24. Haddadi N, Lin Y, Travis G, Simpson AM, Mcgowan EM, Nassif NT. PTEN/PTENP1: 'Regulating the regulator of RTK-dependent PI3K/Akt signalling', new targets for cancer therapy. Molecular Cancer. 2018; 17(1): 37.

25. Dai H, Li X, Li X, et al. Coexisted components of Salvia miltiorrhiza, enhance intestinal absorption of cryptotanshinone via inhibition of the intestinal P-gp. Phytomedicine. 2012; 19(14): 1256-1262.

26. Zhang W, Yu W, Cai G, et al. A new synthetic derivative of cryptotanshinone KYZ3 as STAT3 inhibitor for triple-negative breast cancer therapy. Cell Death Dis. 2018; 9(11): 1098

27. Wang Y, Lu H L, Liu Y D, et al. Cryptotanshinone sensitizes antitumor effect of paclitaxel on tongue squamous cell carcinoma growth by inhibiting the JAK/STAT3 signaling pathway. Biomedicine \& Pharmacotherapy. 2017; 95: 1388-1396.

28. Kim E J, Sun $Y$ K, Kim S M, et al A novel topoisomerase 2a inhibitor, cryptotanshinone, suppresses the growth of PC3 cells without apparent cytotoxicity. Toxicology \& Applied Pharmacology. 2017; 330: 84-92.

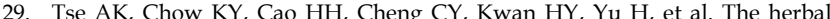
compound cryptotanshinone restores sensitivity in cancer cells that are resistant to the tumor necrosis factor-related apoptosis-inducing ligand. Journal of Biological Chemistry. 2013; 288(41): 29923-33.

30. Very N, Vercoutter-Edouart AS, Lefebvre T, Hardivillé S, El Yazidi-Belkoura I. Cross-Dysregulation of O-GlcNAcylation and PI3K/AKT/mTOR Axis in Human Chronic Diseases. Front Endocrinol (Lausanne). 2018; 9: 602.

31. Yim CY, Bikorimana E, Khan E, et al. G0S2 represses PI3K/mTOR signaling and increases sensitivity to $\mathrm{PI} 3 \mathrm{~K} / \mathrm{mTOR}$ pathway inhibitors in breast cancer. Cell Cycle. 2017; 16(21): 2146-2155.

32. Ching $\mathrm{CB}$, Hansel DE. Expanding therapeutic targets in bladder cancer: the PI3K/Akt/mTOR pathway. Laboratory Investigation. 2010; 90(10): 1406-14.

33. Zeng S, Zhu Y, Ma A H, et al. The Phosphatidylinositol 3-kinase Pathway as a Potential Therapeutic Target in Bladder Cancer. Clin. Cancer Res. 2017; 23: 6580-91.

34. Kim SA, Kang OH, Kwon DY. Cryptotanshinone Induces Cell Cycle Arrest and Apoptosis of NSCLC Cells through the PI3K/Akt/GSK-3 $\beta$ Pathway. Int J Mol Sci. 2018; 19(9): 2739.

35. Ke F, Zheng W, Song X, Qiang M, Hu Y, Lin J, et al. Cryptotanshinone induces cell cycle arrest and apoptosis through the JAK2/STAT3 and PI3K/Akt/NFKB pathways in cholangiocarcinoma cells. Drug Des Devel Ther. 2017; 11: 1753-66.

36. Zhang J, Wen G, Sun L, Yuan W, Wang R, Zeng O, et al. Cryptotanshinone inhibits cellular proliferation of human lung cancer cells through downregulation ofIGF-1R/PI3K/Akt signaling pathway. Oncology Reports. 2018; 40: 2926-34.

37. Zhang L, Chen C, Duanmu J, Wu Y, Tao J, Yang A, et al. Cryptotanshinone inhibits the growth and invasion of colon cancer by suppressing inflammation and tumor angiogenesis through modulating MMP/TIMP system, $\mathrm{PI} 3 \mathrm{~K} / \mathrm{Akt} / \mathrm{mTOR}$ signaling and HIF-1a nuclear translocation. International immunopharmacology. 2018; 65: 429-37.

38. Dasari VR, Kaur K, Velpula KK, et al. Upregulation of PTEN in glioma cells by cord blood mesenchymal stem cells inhibits migration via downregulation of the PI3K/Akt pathway. PLoS One. 2010; 5(4): e10350.

39. Dillon LM, Miller TW. Therapeutic targeting of cancers with loss of PTEN function. Curr Drug Targets. 2014; 15(1): 65-79. 